\title{
Technical Maturation of the SpaceLiner Concept
}

\author{
Martin Sippel, Tobias Schwanekamp, Carola Bauer, Nicole Garbers, Arnold van Foreest \\ Space Launcher Systems Analysis (SART), DLR, Bremen, Germany \\ Ulf Tengzelius \\ Swedish Defense Research Agency FOI, Stockholm, Sweden \\ Aron Lentsch \\ Orbspace Engineering, Podersdorf, Austria
}

DLR's launcher systems analysis division is investigating since a couple of years a visionary, extremely fast passenger transportation concept reaching the edges of space based on rocket propulsion. Work is now focusing on the iterative sizing of all major subcomponents in nominal and off-nominal flight conditions. The paper describes the recent technical progress achieved in the SpaceLiner 7 configuration supported by the EU-funded studies FAST20XX (Future high-Altitude high-Speed Transport 20XX) and CHATT (Cryogenic Hypersonic Advanced Tank Technologies). The focus of the paper is on all system aspects of the reference vehicle's preliminary design including its nominal trajectory and first assessment of its environmental impact.

$\begin{array}{ll}\text { CAD } & \text { computer aided design } \\ \text { GLOW } & \text { Gross Lift-Off Mass } \\ \text { LH2 } & \text { Liquid Hydrogen } \\ \text { LOX } & \text { Liquid Oxygen } \\ \text { NPSP } & \text { Net Positive Suction Pressure } \\ \text { MECO } & \text { Main Engine Cut Off } \\ \text { MR } & \text { mixture ratio } \\ \text { RCS } & \text { Reaction Control System } \\ \text { RLV } & \text { Reusable Launch Vehicle } \\ \text { TPS } & \text { Thermal Protection System } \\ \text { TRL } & \text { Technology Readiness Level }\end{array}$

Subscripts, Abbreviations

\section{Introduction}

A strategic vision of DLR which ultimately has the potential to enable sustainable low-cost space transportation to orbit is under technical evaluation since a couple of years. The number of launches per year should be strongly raised and hence manufacturing and operating cost of launcher hardware should dramatically shrink. The obvious challenge of the vision is to identify the very application creating this new, large-size market.

Ultra long distance travel from one major business center of the world to another major agglomeration on earth is a huge and mature market. Since the termination of Concorde operation, intercontinental travel is restricted to lowspeed, subsonic, elongated multi-hour flight. An interesting alternative to air-breathing hypersonic passenger airliners in the field of future high-speed intercontinental passenger transport vehicles might be a rocket-propelled, suborbital craft. Such a new kind of 'space tourism' based on a two stage RLV has been proposed by DLR under the name SpaceLiner [1]. Ultra long-haul distances like Europe - Australia could be flown in 90 minutes. Another interesting intercontinental destination between Europe and North-West America could be reduced to flight times of slightly more than one hour.

Ultra-fast transportation far in excess of supersonic and even potential hypersonic airplanes is definitely a fundamental new application for launch vehicles. By no more than partially tapping the huge intercontinental travel and tourism market, production rates of RLVs and their rocket engines could increase hundredfold which is out of reach for all other known earth-orbit space transportation. The fast intercontinental travel space tourism, not only attracting the leisure market, would, as a byproduct, also enable to considerably reduce the cost of space transportation to orbit. 


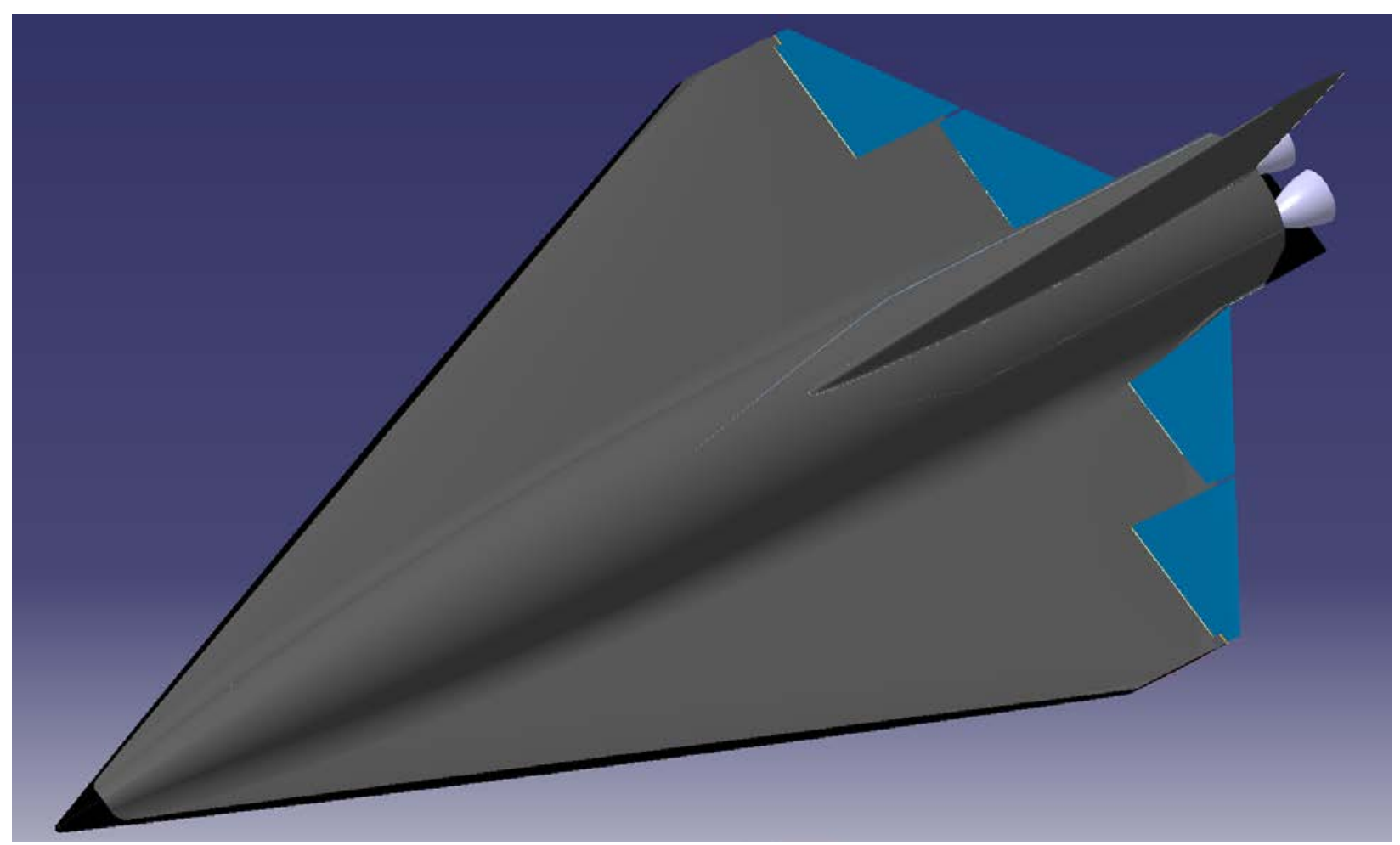

Figure 1: The SpaceLiner vision of a rocket-propelled intercontinental passenger transport, the latest configuration 7-1 is shown, could push spaceflight further than any other credible scenario

The functionality of rocket propulsion is a proven technology since decades and their performance characteristics are well known. Furthermore, a rocket powered RLV-concept like the SpaceLiner is more attractive because the flight durations are two to three times lower than those of even the most advanced airbreathing systems. Although additional times for travel are to be accounted, the actual time needed for travelling with the SpaceLiner might still be reduced by $75 \%$ to $80 \%$ compared to conventional subsonic airliner operation [6]. In contrast to the first generation of SST, thus a substantial advantage in travel times and hence improved business case can be expected. A first assessment of the SpaceLiner's potential business case is described in the references 1, 2, and 5. A more detailed market analyses is currently ongoing in order to find out who might be interested in using the SpaceLiner in the future for travelling.

\section{General Description of SpaceLiner concept}

\section{A. Status of Previous Technical Development}

First proposed in 2005 [1], the SpaceLiner is under constant development and descriptions of some major updates have been published since then $[2,3,4,6]$.

Different configurations in terms of propellant combinations, staging, aerodynamic shapes, and structural architectures have been analyzed. A subsequent configuration numbering has been established for all those types investigated in sufficient level of detail. The genealogy of the different SpaceLiner versions is shown in Figure 2. The box is marking the configuration trade-offs performed in FAST20XX in 2009/10.

These configuration studies supported the definition of the next reference configuration SpaceLiner7 which is now reaching a matured status described in this paper. The level of engineering detail of the traded configurations was not exactly the same as for the previous reference SpaceLiner2 type. E.g. full CAD models have not always been generated. However, obtained data of the interim research configurations 3, 4, 5, and 6 are at sufficiently high quality because they have been iteratively sized with careful scaling of the reference mass break-down, preliminary aerodynamic sizing and always trajectory optimization. An overview on these configurations can be found in [11]. 


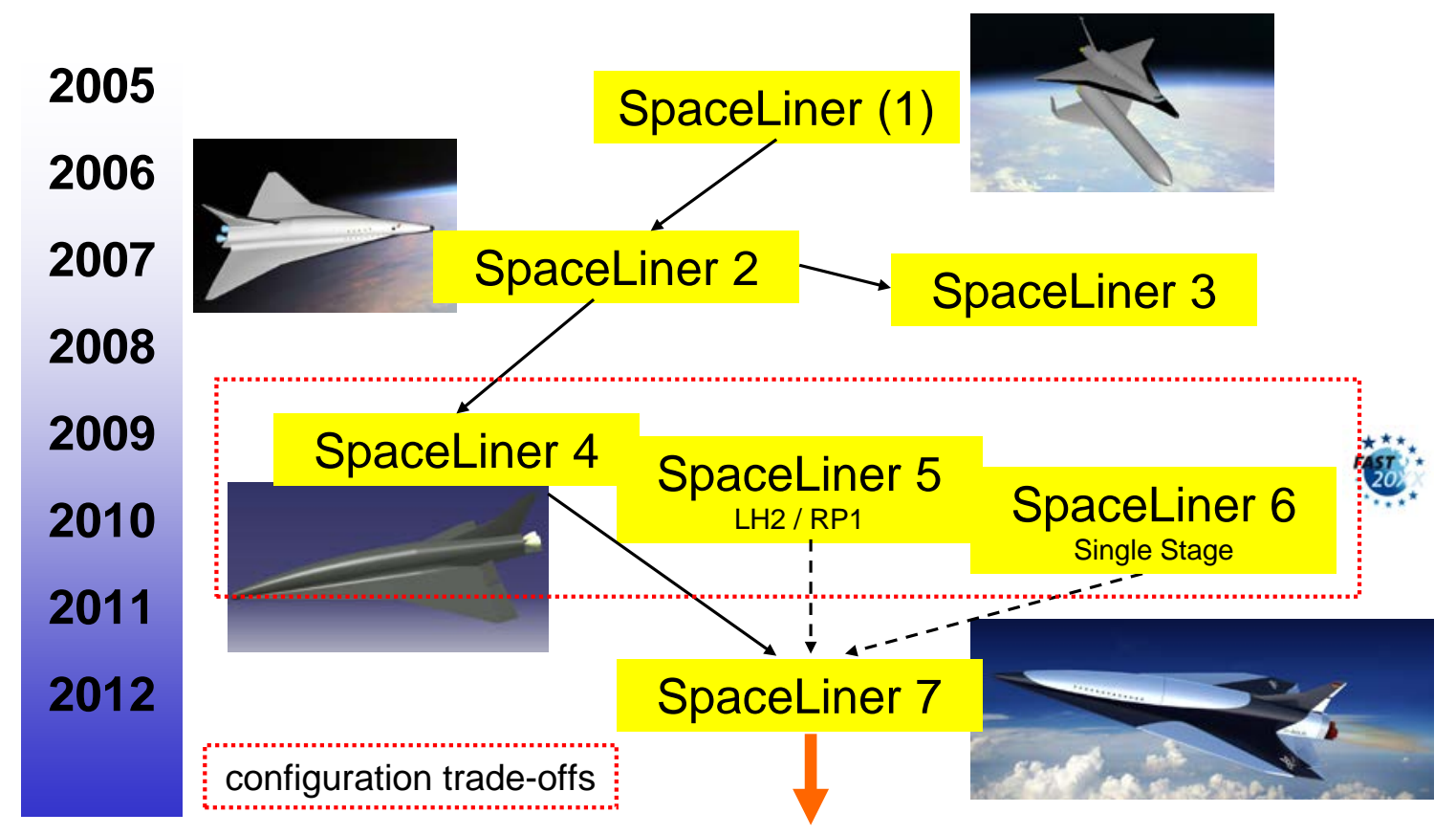

Figure 2: Evolution of the SpaceLiner concept

The general baseline design concept consists of a fully reusable booster and orbiter (including the passengers) arranged in parallel. All engines should work from lift-off until MECO. A propellant crossfeed from the booster to the orbiter is foreseen up to separation to reduce the overall size of the orbiter stage.

\section{B. Mission Definition}

The ambitious west-bound Australia - Europe mission has been used as the reference case since the beginning of the SpaceLiner investigations. This flight distance should be served for 50 passengers on a daily basis in each direction. Several other, shorter intercontinental missions exist, which potentially generate a larger market demand. For this reason a SpaceLiner configuration derivative has been studied, which could transport up to 100 passengers [34]. In order to keep the number of different stage configurations at the lowest possible level, the potentially interesting flight destinations have been divided into three classes:

- Class 1: Reference mission (up to $17000 \mathrm{~km}$ ) Australia - Europe with 50 passengers orbiter and large reference booster

- Class 2: Mission (up to $12500 \mathrm{~km}$ ) e.g. Dubai - Denver with increased 100 passengers orbiter and large reference booster

- Class 3: Mission (up to $9200 \mathrm{~km}$ ) e.g. Trans-Pacific with increased 100 passengers orbiter and reduced size booster

These three mission classes could be flexibly served by a suitable combination of four different vehicles (however with a lot of commonality in subcomponents like engines): 50 and 100 Passenger orbiter stage and large and shortened booster.

\section{Sophisticated Trajectory Optimization combined with Vehicle Design Optimization}

A major step forward has been achieved with the system investigations trading a skipping vs. a hypersonic gliding trajectory while also taking into account preliminary sizing of the thermal protection system. Ref. 15 demonstrates by trajectory optimization using the AeroSpace Trajectory Optimisation Software ASTOS that gliding at an angleof-attack with optimum L/D is beneficial for the overall system mass. Hence, this flight mode has now been selected for the ambitious Australia - Europe reference design mission. Ongoing activities also look into a partially ballistic trajectory right after MECO as a potentially interesting alternative.

The best mixture ratio of the SpaceLiner main propulsion system along its mission has been defined by system analyses optimizing the full nominal trajectory. A trajectory optimization under the consideration of all relevant mission constraints and objectives is performed for the SpaceLiner4 using again ASTOS with the same configuration 2010 data [15]. Several MR-optimization options have been investigated with ASTOS always aiming 
for a minimization of (booster) propellant mass. Nominal engine MR control at two engine operation points (6.5 from lift-off until reaching the $2.5 \mathrm{~g}$ acceleration and 5.5 afterwards) with relatively short transients in between is found most promising. Figure 3 compares the actual calculated engine $I_{s p}$ at each trajectory point for the reference configuration (red lines) with the MR optimized $\mathrm{I}_{\mathrm{sp}}$ (black lines). The booster engines are represented by continuous lines, whereas the orbiter engine by dashed lines. The increased mixture ratio enables a better low-altitude $I_{s p}$ than the reference $M R=6$ case. Almost exactly at the trajectory point when the $I_{s p}$ curve for adaptable MR would dive below the reference $I_{\mathrm{sp}}$ the optimizer switches to lower mixture ratio and hence better vacuum $\mathrm{I}_{\mathrm{sp}}$. (In Figure 3 visible approximately at $80 \mathrm{~s}$ to $90 \mathrm{~s}$ after lift-off; depending on the stage.) This approach allows for a significant propellant saving on the booster of $38 \mathrm{Mg}$, a reduction of $5 \%$ compared to the reference configuration without MR adaptation. That result is readily understandable because the specific impulse during the mission is superior by a few seconds to the reference case with fixed engine mixture [19]..

After completion of the trajectory optimization, the obtained mission average tank MR in orbiter and booster remains very close to 6.0. It is interesting to note that after booster separation the orbiter engines in the best optimized case switch back to high MR (high thrust) to switch again after 100 seconds to low MR (high vacuum $\mathrm{I}_{\mathrm{sp}}$ ). Therefore, the orbiter tank MR remains closely around 6, allowing a more compact stage design than lower tank MR and still having the vehicle's best performance.

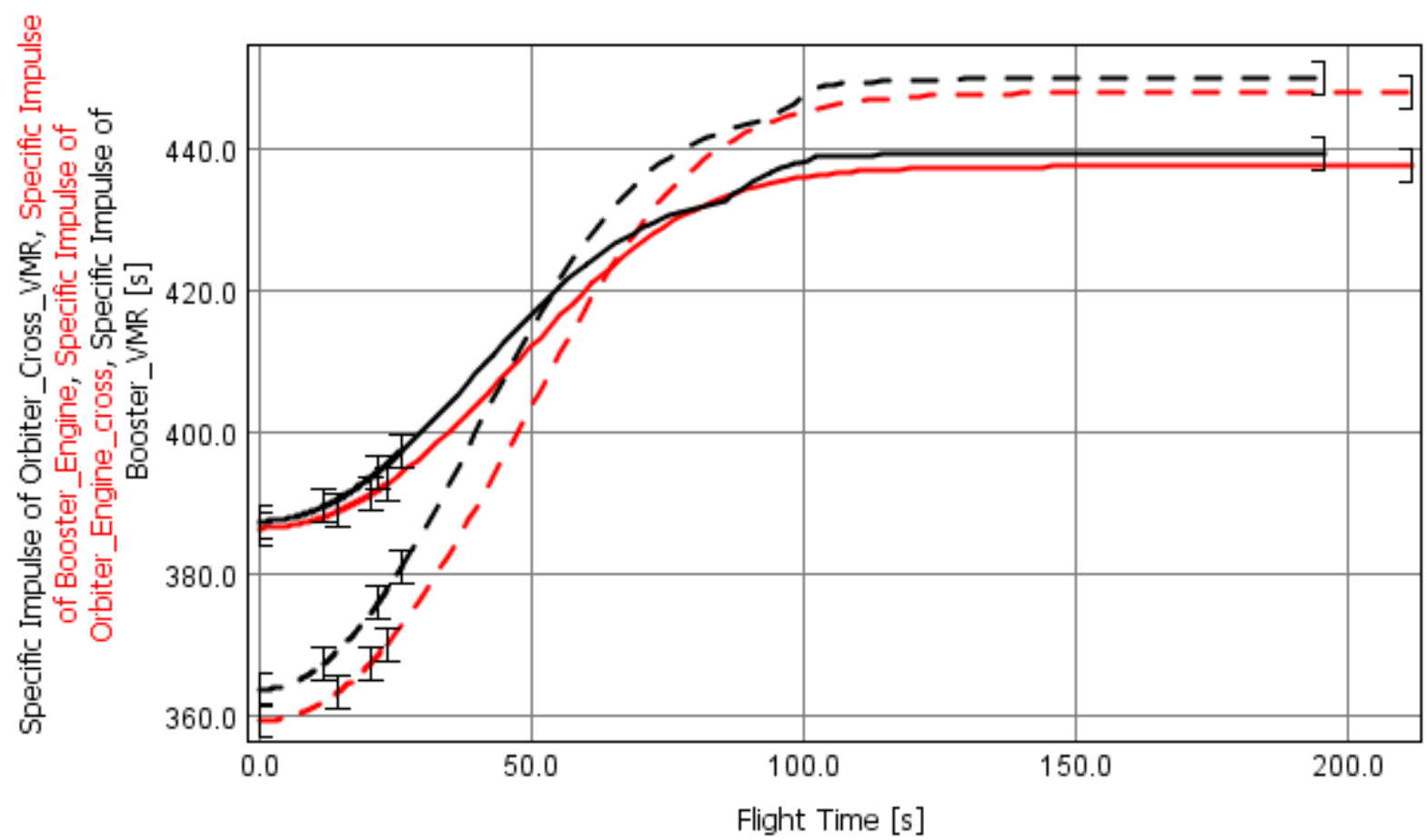

Figure 3: Actual engine $I_{s p}$ along SpaceLiner4 joint booster-orbiter ascent in case of fixed (red) and adaptive (black) MR

The definition of SpaceLiner 7 has been based subsequently on engines with a variable MR-range from 5.5 to 6.5 .

\section{Environmental impact study in FAST20XX}

On a first look, the environmental impact of the LOX-LH2 propelled SpaceLiner is relatively benign and seems to be much less critical than for airbreathing concepts. The rocket concept is releasing even less exhaust gases into the atmosphere than today's commercial airliners because the engines do not burn the air.

Within the EU-funded FAST20XX (Future high-Altitude high-Speed Transport 20XX) project [9, 10] a first quantified environmental impact assessment of the SpaceLiner operation has been done by FOI. The focus has been on noise and emissions, which are considered to be major potential environmental obstacles for ultrafast suborbital traffic. The investigated configuration has been the SpaceLiner 4 in its Europe - Australia reference mission and ASTOS trajectory data comparable to those presented in [15] have been used as an input source. 


\section{Launch noise}

In order to quantify possible noise levels from a SpaceLiner launch, an approach based on a semi-empiric method given in ref. 21 was taken. With data given therein, it is possible to predict the noise source strength, from general nozzle and flow parameters, as a function of frequency and sound propagation direction. Errors in noise level estimates with the given approach are judged to be within +/- $6 \mathrm{~dB}$ [21].

A computer code was established around the data extended with the inclusion of:

- Arbitrary trajectories

- Doppler effect

- Sound source strength due to

- $\quad$ altitude (static pressure)

- relative velocity ambient air / nozzle exhaust

- Noise propagation (spherical propagation)

- Dissipation, i.e. distance dependent damping as a function of humidity

- Noise carpet generation including onset of sonic boom ground hit

While Space Shuttle noise with a level of $90 \mathrm{dBAmax}$ has been reported at a distance of $9384 \mathrm{~m}$ [22], the same level may be expected at around $6 \mathrm{~km}$ from the SpaceLiner 4 launch site. Predicted SpaceLiner launch noise levels suggest that a launch site has to be situated at quite some distance away from residential areas, which has already been the baseline assumption since the start of the project (see e.g. [7]). The ascent sonic boom noise is predicted to reach noise levels locally up to 120 dBCSEL, and above 95 dBCSEL within an area of about $10000 \mathrm{~km}^{2}$, judged as an even stronger noise impact than the launch noise itself. This situation requires uninhabited areas (e.g. open sea) someway in the downrange flight direction as it is the case for all of today's rocket launch sites.

\section{Sonic boom noise}

The sonic boom noise carpet for a reference flight path, from Netherlands over Eastern Europe, Asia, Indonesia to eastern Australia is studied with the PCboom4 code [23]. Altitude and travelled distance for the east-bound reference trajectory from ASTOS has been used. For the launch/ascent phase, with the booster, the SpaceLiner shape factor in PCboom4 runs was selected as "Shuttle", input "8" (without modeled plume). The resulting PCboom4 sound pressures, read by a Matlab script and presented as iso-dB (CSEL) contour lines in Google Earth, are shown in Figure 4 as an example.

As expected very high levels, $120 \mathrm{~dB}$ CSEL, are found immediately after the first sonic boom hits ground. The resulting noise carpet related to the first part of the SpaceLiner decent (from Europe to central Asia) represents a weak deceleration at high altitudes, with strongly reduced noise levels compared with the initial ascent and acceleration phase. Although some sonic boom noise might reach certain areas on ground even with the SpaceLiner flying at very high altitudes, measurements of the Space Shuttle flying at about $60 \mathrm{~km}$ delivered boom overpressure levels approximately $90 \%$ lower than those of XB-70 and Concorde [24]. Further east, over East Asia, Indonesia and northern Australia with the SpaceLiner at lower altitudes, the sonic boom ground levels gets higher and are estimated in certain regions in the range of 85 to $95 \mathrm{~dB}$ CSEL, i.e. may be considered as "high energy impulsive noise“. The most critical situation, in the given example would be reached for the last $500 \mathrm{~km}$, with levels above 95 dBCSEL up to 98 dBCSEL. Tailoring of the flight trajectory might be necessary to avoid any unacceptable noise levels in certain regions. Thus, also the selection of suitable landing sites is effected by the vehicle's noise in the final supersonic flight approach.

\section{Atmospheric emission}

The considered propellants for the SpaceLiner (hydrogen and oxygen) can be regarded as environmentally friendly in comparison with many other common aircraft/rocket fuels because only water steam and hydrogen, which are natural occurring trace gases in the atmosphere, leave the exhaust nozzle. Nevertheless, some matters have to be studied further before the environmental emissions impact from a SpaceLiner vehicle in regular traffic can be assessed. With regard to the SpaceLiner it is to be considered that stratospheric water vapor effect the Earth's radiation budget and play a strong role in stratospheric chemistry, and also in processes that could impact the ozone layer. The SpaceLiner fleet would be the biggest anthropogenic direct source of $\mathrm{H}_{2} \mathrm{O}$ within the mid/upper stratosphere, where the only additional, and much smaller, sources today are from space launches. 


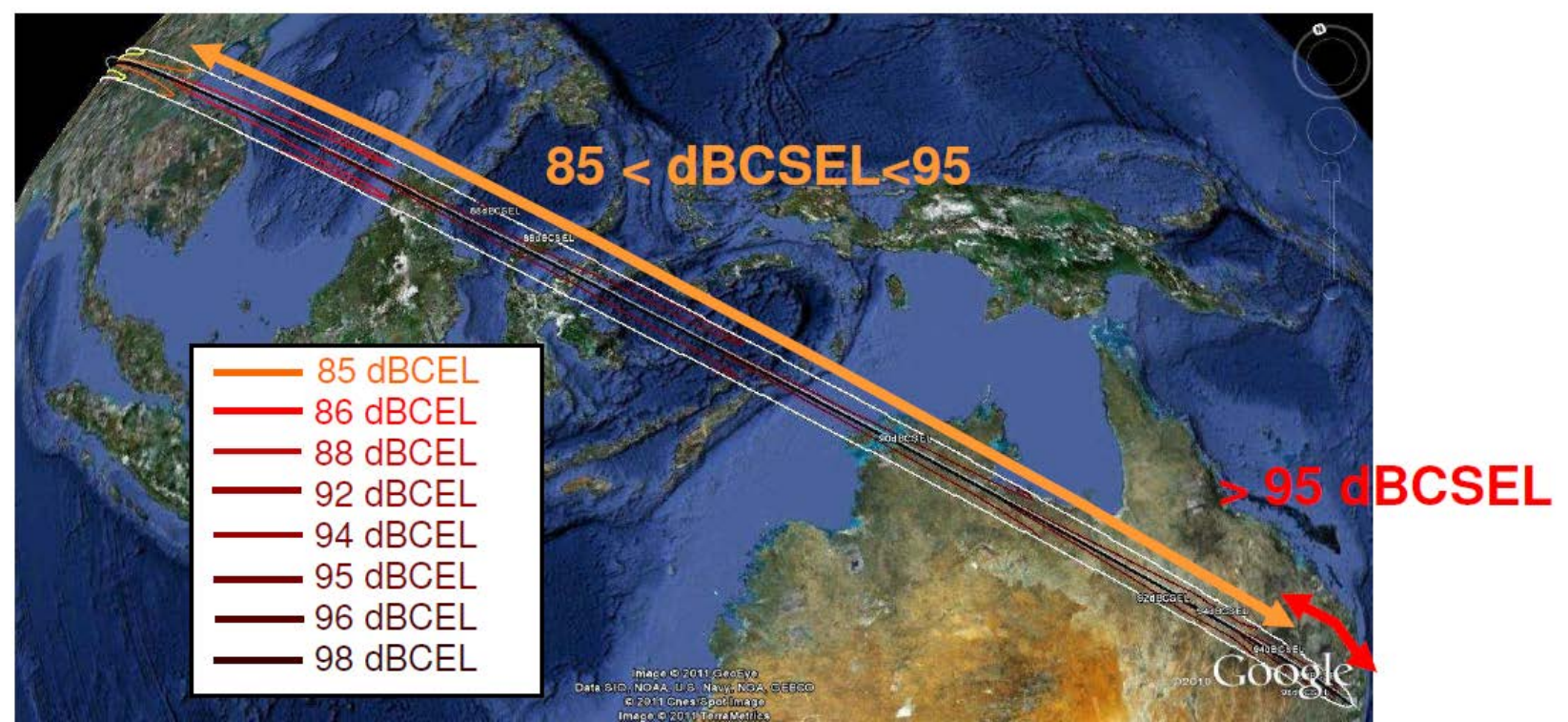

Figure 4: Simulated potential sonic boom noise carpet of SpaceLiner passage over East Asia and Indonesia, with final approach over Australia

The actual amount of water and its distribution in the atmosphere can be derived from trajectory simulation of the SpaceLiner. The impact on Earth's climate is difficult to assess without complex modeling. Extrapolation of results from other aircraft climate studies, to ozone concentrations and global warming effects for an operational SpaceLiner fleet were made. Such an approach is highly approximate due to the different altitude distributions but has been accepted here as a first rough approximation. For an assumed traffic of five daily flights on the example trajectory Europe - Australia results for ozone changes indicate a total column decrease (steady state response) of $0.004-0.03 \%{ }^{*}$ in the total northern hemisphere. Locally above the South Pole decreases of the total column are estimated to reach 6-7 times this value [26]. The global warming effect, taken as mean earth surface temperature (over time and the globe as a steady state level for a sudden ramp or step function) is in the same way predicted to rise 0.6 to $2.5 \mathrm{mK}^{\dagger}$ for five daily SpaceLiner reference flights. As a comparison the future (subsonic) air traffic is estimated to increase the temperature by 30 to 100 times that value (ca. $60 \mathrm{mK}$ ). The values or ozone loss, as well as temperature changes from SpaceLiner could be assumed as linearly dependent and therefore scalable for any other daily traffic intensities.

Nitrogen Oxides (NOx) have a strong impact on global warming and are a major concern of all aircraft with airbreathing propulsion. Theoretically, the SpaceLiner exhaust is completely free of NOx. However, a potential NOx generation source is in the exhaust, where the free-stream air is mixed with the hot $\mathrm{H}_{2} \mathrm{O}$ and $\mathrm{H}_{2}$ exhaust gases. In order to examine this risk a CFD RANS computation of the SpaceLiner exhaust nozzle was carried out by FOI. The result from the analysis was that almost no NOx will be produced within the exhaust, mainly due to the fast expansion and because not sufficiently high temperatures will be achieved within the plume mixing layers. This is consistent with data on the SSME of the Space Shuttle.

\section{Maturation to SpaceLiner 7-1}

Since the last overview paper on the SpaceLiner [15] significant technical progress related to the overall launch configuration as well as to both stages, the reusable booster and the orbiter or passenger stage, has been achieved. The current arrangement of the two vehicles at lift-off is presented in Figure 5. Stage attachments are following a classical tripod design. The axial thrust of the booster is introduced through the forward attachment from booster intertank into the nose gear connection structure of the orbiter. The aft attachment takes all side and maneuvering loads. The option of a belly to belly connection is not preferred for two reasons: A strong unintended aerodynamic interaction of the two wings and propellant crossfeed lines on the booster which would be directly affected by

\footnotetext{
* Span in ozone column reduction is given by the span in $\mathrm{H}_{2} \mathrm{O}$ stratospheric lifetime given by IPCC, 1-6 years. [25]

${ }^{\dagger}$ Here the span is given by whether original data are extrapolated to higher altitudes or staying at the function limit given in ref. 27.
} 
hypersonic flow during reentry of this stage. Thus, the arrangement in Figure 5 is the current baseline, however, it is still subject to trade-offs and optimization and hence might be changed in the future.
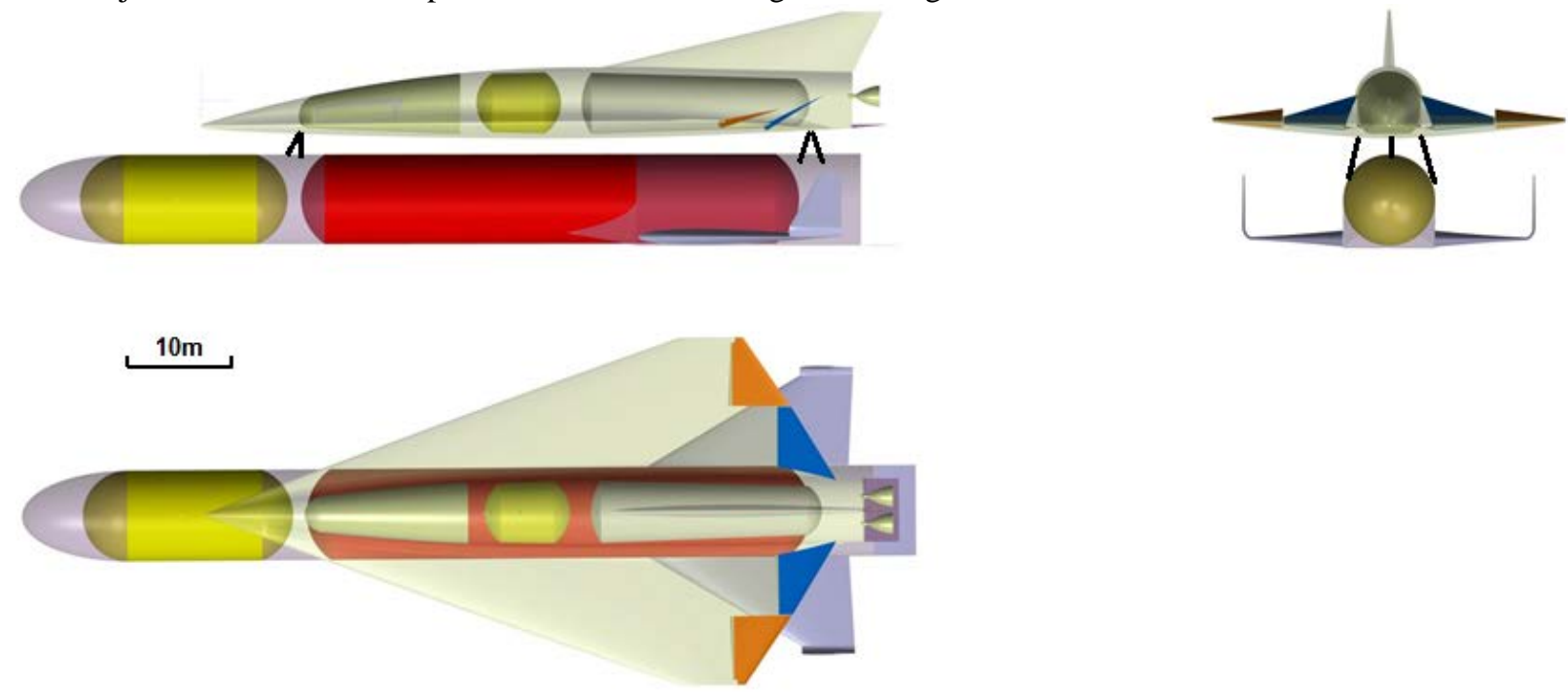

Figure 5: Sketch of latest SpaceLiner 7-1 launch configuration with passenger stage on top and booster stage at bottom position with approximate location of stage attachment

\section{A. Definition of reusable booster stage}

Since the beginning of the SpaceLiner investigations the reusable booster stage has always been somewhat in the shadow of the orbiter which is carrying the passengers and is experiencing the highest thermal loads and reaching maximum velocity and altitude. However, the booster is a also very high performance launch vehicle stage and critical to the overall success of the SpaceLiner configuration.

The separation Mach number of the reference mission is approximately 12.5 which is already too high for any powered fly-back with acceptable amount of on-board fuel. A down-range landing side, if available at all, is not attractive for logistical reasons. Therefore, the patented in-air-capturing method [28, 29] should be used. The empty stage is to be captured during subsonic descent and subsequently towed back by an airplane and finally released for an autonomous gliding landing on a runway. In simulations of the SpaceLiner booster's reentry it is always assured that sufficient time for the in-air-capturing maneuver is available.

Several booster design trade-offs have been performed always carefully considering the trimmability and flyability of the aerodynamic configuration [17]. Also flexible wings (e.g. foldable or rotatable) could be interesting because the aerodynamic interference of both stages in mated ascent would become significantly lower. Such a design has been systematically investigated by DLR for another booster configuration [30] and was assessed as feasible. However, a flexible wing design is always related to additional structural and mechanical system mass.

The current SpaceLiner 7-1 booster geometry is more conventional with two large tanks with separate bulkheads for LOX and LH2 which resembles the Space Shuttle External tank lay-out. The only major additions to the ET are an ogive nose for aerodynamic reasons and for housing subsystems, the propulsion system, and the wing structure with landing gear. The overall size of the booster had been recently scaled-up and is now reaching significant dimensions of more than $80 \mathrm{~m}$ in length, if the ambitious reference mission is to be served. Major data are listed in Table 1.

Table 1: Geometrical data of SpaceLiner 7-1 booster stage

\begin{tabular}{|c|c|c|c|c|c|c|}
\hline length [m] & span [m] & height [m] & $\begin{array}{c}\text { fuselage } \\
\text { diameter [m] }\end{array}$ & $\begin{array}{c}\text { wing leading } \\
\text { edge angle } \\
\text { [deg] }\end{array}$ & $\begin{array}{c}\text { wing Pitch } \\
\text { angle [deg] }\end{array}$ & $\begin{array}{c}\text { wing } \\
\text { Dihedral } \\
\text { angle [deg] }\end{array}$ \\
\hline 83.5 & 26.5 & 8.7 & 8.6 & 60 & 0 & 0 \\
\hline
\end{tabular}


A structural pre-dimensioning of the SpaceLiner 7-1 booster is currently performed at FOI in Sweden and final results are not yet available. For the design of these structural members inspiration was taken from the current conventional way of construction aircraft fuselages called semi-monocoque. The semi-monocoque utilizes a substructure of formers and stringers that help prevent local bending of the stressed skin and relieves it of some of the global bending stresses. The two tanks are part of the load carrying structure and therefore the structural members are placed internally. The well-proven aluminum alloy 2024 is chosen as material for the booster's primary structure. The structure of the wing also follows aircraft convention with ribs to make up the shape of the wing profile and spars to carry the main bending load. A von Mises stress plot of the tank pressure load case is shown in Figure 6. Maximum stresses are roughly one fourth of the material limits.

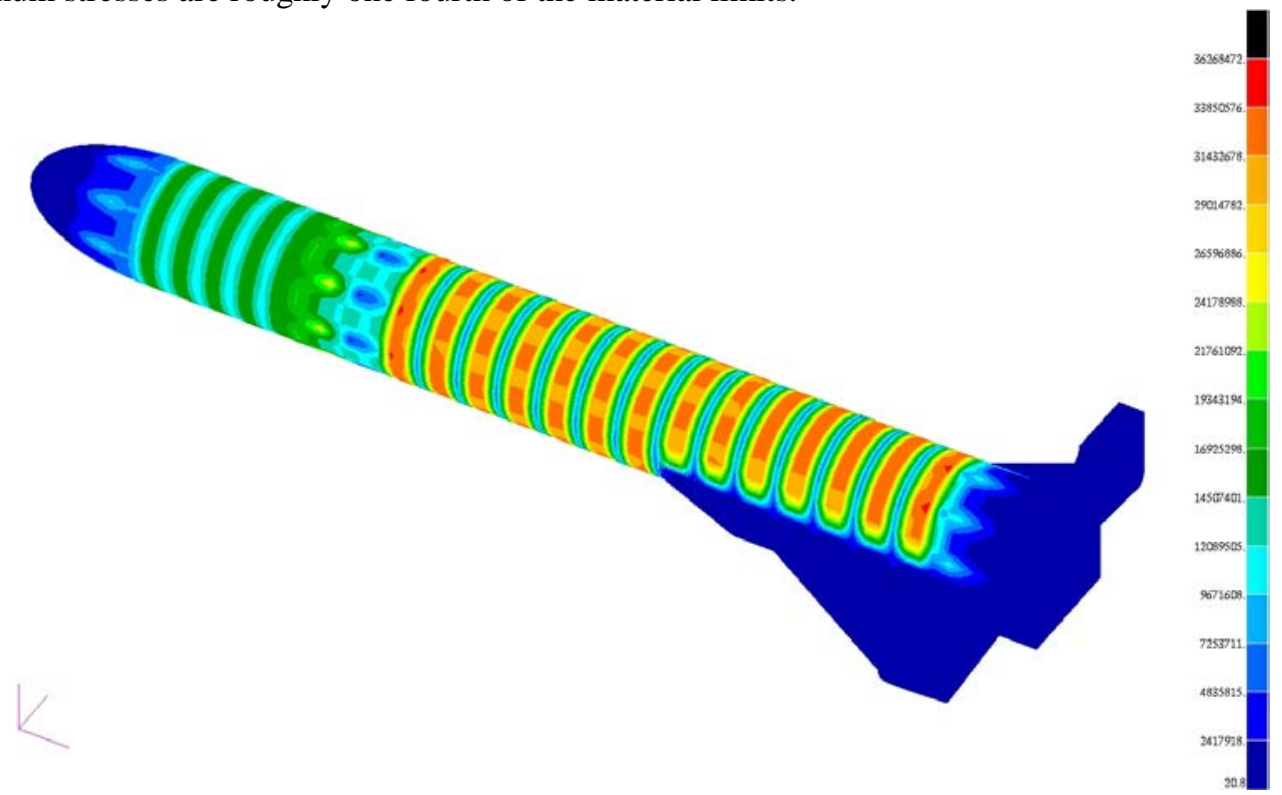

Figure 6: Von Mises stresses [Pa] in SpaceLiner 7-1 booster structure from FEM analysis at FOI

The FOI structural design is not only looking into static load analyses but is also addressing structural dynamic issues which are potentially critical for the feasibility of the design. During the Eigenfrequency analysis it became necessary to increase the stiffness of the structure. Therefore the skin is now a sandwich made up of CFRP face sheets and polymer foam in-between.

Another critical point has been detected by Eigenmode analysis: The huge winglets are keeping the first few Eignenmodes of the wings as low as around $4.5 \mathrm{~Hz}$ and below the global bending mode of the fuselage. In order to avoid this unfortunate situation, it might become necessary to reposition the lateral stability surfaces to another vehicle station, preferably the fuselage. However, then an integration challenge will arise for the launch configuration which could require the attachment of foldable or movable fins.

As the structural pre-design is not yet finished, all dry mass data are still based on empirical estimation relations derived of launch vehicles or hypersonic transport studies (see Table 2). System margins of $14 \%$ (12 \% for propulsion) are added to the estimated mass data.

Table 2: Mass data of SpaceLiner 7-1 booster stage

\begin{tabular}{|c|c|c|c|c|c|c|}
\hline $\begin{array}{c}\text { Structure } \\
{[\mathrm{Mg}]}\end{array}$ & $\begin{array}{c}\text { Propulsion } \\
{[\mathrm{Mg}]}\end{array}$ & $\begin{array}{c}\text { Subsystem } \\
{[\mathrm{Mg}]}\end{array}$ & TPS $[\mathrm{Mg}]$ & $\begin{array}{c}\text { Total dry } \\
{[\mathrm{Mg}]}\end{array}$ & $\begin{array}{c}\text { Total } \\
\text { propellant } \\
\text { loading }[\mathrm{Mg}]\end{array}$ & GLOW [Mg] \\
\hline 84.1 & 36 & 21.1 & 23.8 & 165.1 & 1290 & 1454.8 \\
\hline
\end{tabular}

\section{B. Shape optimization of orbiter/passenger stage}

The Mach number range of SpaceLiner orbiter stretches from the hypersonics through the transonic regime to the low speed subsonic landing approach. An extensive study on the different geometrical options for the optimization 
of the hypersonic aerodynamic and aerothermodynamic characteristics of the SpaceLiner has been concluded at DLR in 2010 [14].

The SpaceLiner7 is the first SpaceLiner configuration characterized by an aerodynamic shape arisen from a fully automated optimization process. In order to consider a wide range of the hypersonic trajectory, three points with different flight Mach numbers (20.1, 13.6, 6.0) and corresponding altitudes were chosen for the optimization [31]. The SpaceLiner 2 and 4 configurations were taken as the baseline geometries to optimize L/D considering aerothermal loads. A set of geometrical design parameters was released to variegate during the optimization process (nose radius, nose length, wing span, chord length, sweep angle, airfoil thickness) while a couple of geometrical and physical constraints were set (e.g. minimum lift, maximum stagnation point heat flux). The final result of the optimizations, a trade-off between the optima of the three trajectory points, already showed considerable improvements in glide ratio and heat loads and pointed out the clear advantages of a single delta wing.

An update of the passenger cabin dimensions identified that the fuselage was not sufficiently large for its accommodation. A sharper nose in conjunction with the need for an applicable adaption of wing and fuselage as well as the demand for a minimum amount of space for subsystems and the passenger cabin led to an increased nose length of $+3.0 \mathrm{~m}$. All these measures resulted in the SpaceLiner 7-0 shape presented in [31].

However, further design refinement of components and subsystems added some mass to the configuration and resulted in a shift in center of gravity. Safe controllability of the vehicle in all flight conditions has to be assured including during abort cases. It has been found even more critical after the mass updates that in nominal flight the optimum L/D range required some small but non-negligible wing flap deflections. Although trimmability of the vehicle was never compromised, the situation was unacceptable for achieving the ambitious flight range requirement. Therefore, the SpaceLiner 7-0 shape of [31] has been again modified in an optimization process. The nose and leading edge section of the new SpaceLiner 7-1 has been left untouched while the aft section has been modified. The most striking difference is a trailing edge angle which affects the center of pressure position in a way that the pitching moment at maximum L/D hypersonic flight is again very close to its trimmed state without any control surface deflection. The aft fuselage height is increased allowing additional fuel to be accommodated without almost any impact on drag and a new vertical stabilizer with very large leading edge inclination is modeled. The new improved shape is shown in Figure 1 and Figure 7.

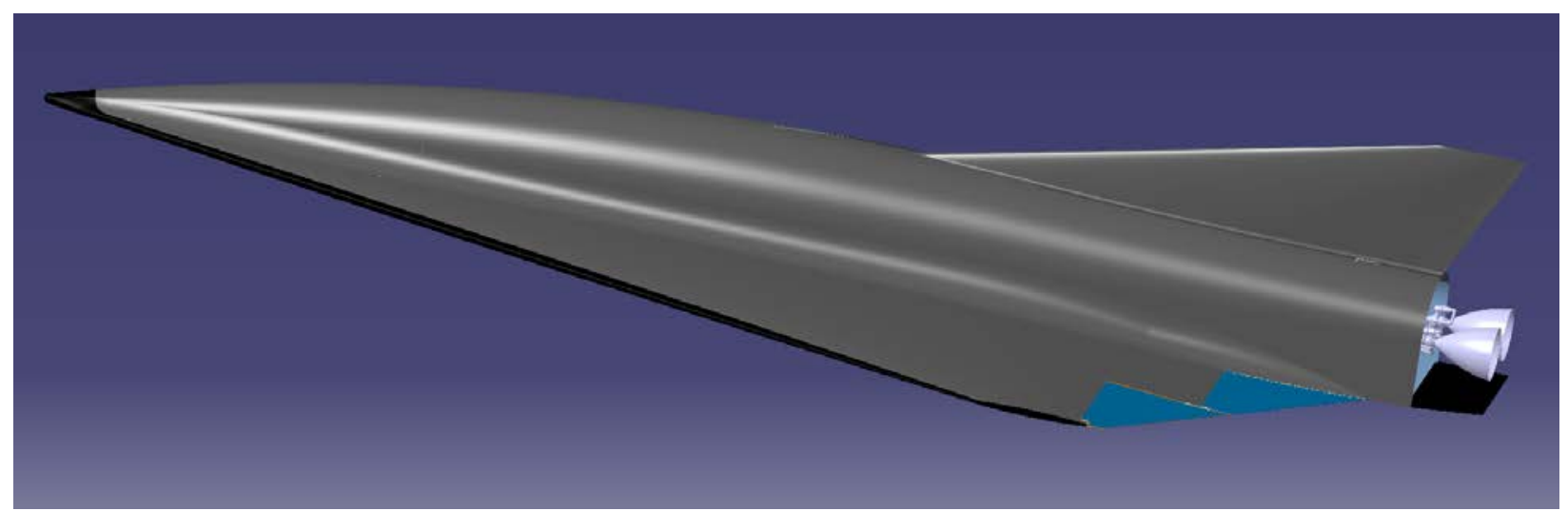

Figure 7: Latest SpaceLiner 7-1 orbiter shape

New, updated aerodynamic data sets have been generated with different numerical tools. The SpaceLiner 7-1 still achieves an excellent hypersonic L/D of 3.5 assuming a fully turbulent boundary layer. Recently ESA has been calculating the new shape with Euler CFD (Figure 8). Obtained results confirm the aerodynamic coefficient data of DLR. 


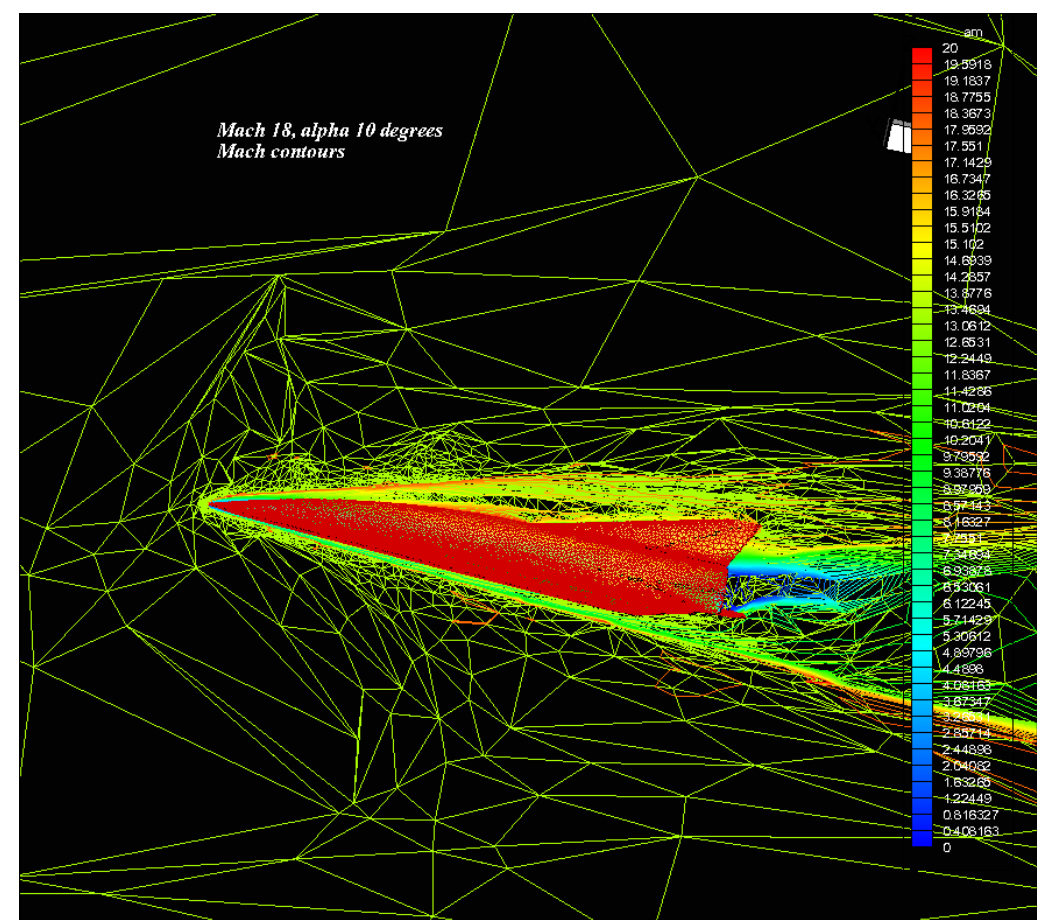

Figure 8: Euler CFD-results of SpaceLiner 7-1 orbiter at $M=18, \alpha=10^{\circ}$ from ESA-ESTEC calculation

Safe controllability of the vehicle in all flight conditions has to be assured including during abort cases. To define the wing flaps of the SpaceLiner, knowledge on the most extreme flight maneuvers is needed. This has been assumed to be an abort scenario starting at the time of booster separation with the passenger stage's propulsion system inoperative. A re-entry trajectory for this case is simulated with the constraint of maximal allowed loads [16]. The wing flaps shown in blue in Figure 1 and Figure 7 are following this sizing approach. The flap's hinge line attachment is influenced by the Space Shuttle example. The overall design will still require a more detailed assessment of efficiency and aerothermodynamic issues in the future.

Major geometry data of the SpaceLiner 7-1 orbiter stage are summarized in Table 3.

Table 3: Geometrical data of SpaceLiner 7-1 orbiter stage

\begin{tabular}{|c|c|c|c|c|c|c|}
\hline length [m] & span [m] & height [m] & $\begin{array}{c}\text { fuselage } \\
\text { diameter [m] }\end{array}$ & $\begin{array}{c}\text { wing leading } \\
\text { edge angle } \\
\text { [deg] }\end{array}$ & $\begin{array}{c}\text { wing Pitch } \\
\text { angle [deg] }\end{array}$ & $\begin{array}{c}\text { wing } \\
\text { Dihedral } \\
\text { angle [deg] }\end{array}$ \\
\hline 65.6 & 33.0 & 12.1 & 6.4 & 70 & 0.4 & 2.65 \\
\hline
\end{tabular}

\section{Subsystem definitions passenger stage}

In the final phase of FAST20XX several SpaceLiner subsystems are preliminarily defined and evaluated. The following sections give an overview on most recent progress.

\section{Main propulsion system}

Staged combustion cycle rocket engines with a moderate 16 MPa chamber pressure have been selected as the baseline propulsion system. The engine performance data are not overly ambitious and have already been exceeded by existing engines like SSME or RD-0120. However, the ambitious goal of a passenger rocket is to considerably enhance reliability and reusability of the engines beyond the current state of the art. The expansion ratios of the booster and orbiter engines are adapted to their respective optimums; while the mass flow, turbo-machinery, and combustion chamber are assumed to remain identical in the baseline configuration.

Two types of staged combustion cycles (one full-flow and the other fuel-rich) have been considered for the SLME and traded by numerical cycle analyses [18]. A Full-Flow Staged Combustion Cycle with a fuel-rich preburner gas turbine driving the LH2-pump and an oxidizer-rich preburner gas turbine driving the LOX-pump is a preferred 
design solution for the SpaceLiner. This approach should allow avoiding the complexity and cost of additional inert gases like Helium for sealing.

In a Full-Flow Staged Combustion Cycle (FFSC), two preburners whose mixture ratios are strongly different from each other generate turbine gas for the two turbo pumps. All of the fuel and oxidizer, except for the flow rates of the tank pressurisation, is fed to the fuel-rich preburner (FPB) and the oxidizer-rich preburner (OPB) after being pressurised by each turbo pump. After the turbine gas created in each preburner work on each turbine they are all injected in hot gaseous condition into the main combustion chamber (MCC). The regenerative cooling of the chamber and the nozzle is made with hydrogen fuel after being discharged by the FTP. The fuel tank pressurization gas is supplied from the fuel line after leaving the regenerative circuit while the oxidizer tank pressurization gas is bled from the oxidizer line behind the OTP discharge and then heated-up in a heat exchanger [18].

The mixture ratios of FPB and OPB are controlled to be 0.7 and 130 so that TET is restricted to around $770 \mathrm{~K}$. at each turbine a bypass line is foreseen for which the flow should be controlled by a hot gas valve in order to allow engine operation in the mixture ratio range from 5.5 to 6.5 without changing TET or excessively raising pre-burner pressures. The limitation of the nominal characteristic conditions should enable an engine lifetime of up to 25 flights. Further, this approach gives some margin to significantly raise engine power in case of emergency by increasing TET beyond the limitation [18].

Table 4 gives an overview about major SLME engine operation data for the nominal MR-range as obtained by cycle analyses. Note that the thrust level has been increased compared to previous engine configurations described in [11, $16,18]$ to take into account the SpaceLiner 7-1 lift-off weight increase.

Table 4: SpaceLiner Main Engine (SLME) technical data

\begin{tabular}{|l|c|c|c|c|c|c|}
\hline & \multicolumn{3}{|c|}{ Booster } & \multicolumn{3}{c|}{ Orbiter } \\
\hline Mixture ratio [-] & 5.5 & 6.0 & 6.5 & 5.5 & 6.0 & 6.5 \\
\hline Chamber pressure [MPa] & 15.1 & 16.0 & 16.9 & 15.1 & 16.0 & 16.9 \\
\hline Fuel-rich Preburner pressure [MPa] & 29.4 & 30.0 & 30.8 & 29.5 & 30.2 & 31.0 \\
\hline Oxidizer-rich Preburner pressure [MPa] & 29.1 & 29.7 & 30.5 & 29.2 & 29.9 & 30.7 \\
\hline Fuel-rich Preburner TET [K] & 732 & 735 & 738 & 720 & 722 & 724 \\
\hline Oxidizer-rich Preburner TET [K] & 773 & 775 & 778 & 772 & 774 & 777 \\
\hline Mass flow per engine [kg/s] & 481 & 517 & 555 & 481 & 518 & 555 \\
\hline Expansion ratio [-] & 33 & 33 & 33 & 59 & 59 & 59 \\
\hline Specific impulse in vacuum [s] & 439 & 437 & 435 & 451 & 449 & 448 \\
\hline Specific impulse at sea level [s] & 387 & 389 & 390 & 357 & 363 & 367 \\
\hline Thrust in vacuum per engine [kN] & 2061 & 2206 & 2356 & 2116 & 2268 & 2425 \\
\hline Thrust at sea level per engine[kN] & 1817 & 1961 & 2111 & 1678 & 1830 & 1986 \\
\hline
\end{tabular}

Cycle analyses results for the full-flow is used for ongoing turbo-machinery pre-sizing. Figure 9 demonstrates the significantly different sizes of the booster and orbiter engines with similar combustion chamber, turbomachinery, and manifolds.

\section{Propellant feed and tank pressurization system}

All main engines of the configuration should work from lift-off until MECO. A propellant crossfeed from the booster to the orbiter is foreseen up to separation to reduce the overall size of the orbiter stage [6]. Tank integration and propellant feed-system definition is performed in CHATT with steady-state flow-simulation along the full powered trajectory. First results for the SpaceLiner 7-1 are presented in [19].

The tank pressurization system is preliminarily designed using the DLR-tool pmp. A preliminary arrangement of feed- and pressurization lines with the tanks of both stages in the mated configuration is shown in Figure 10. The LOX-tanks are pressurized by gaseous oxygen and the hydrogen tanks with gaseous hydrogen. This approach is selected in order to avoid any excessive use of expensive and rare helium. 


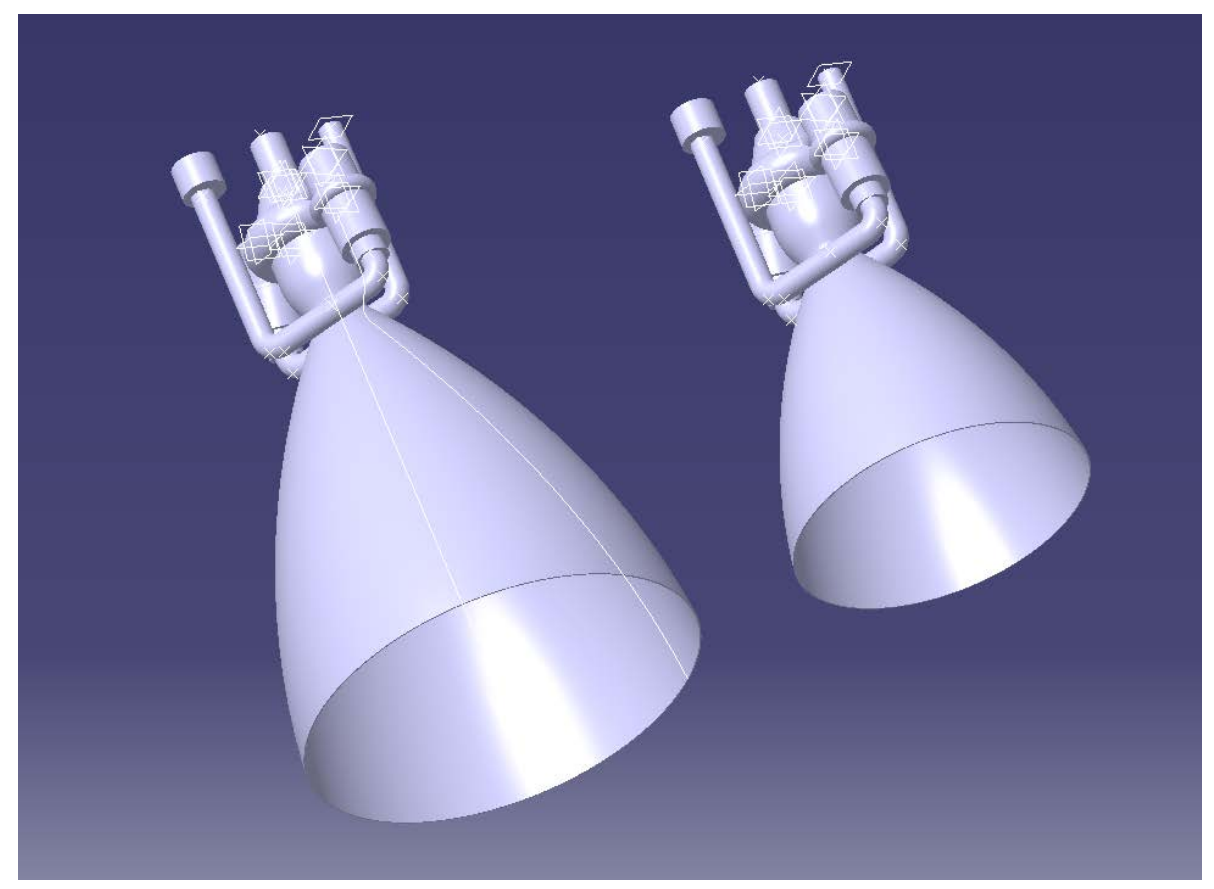

Figure 9: SLME CAD geometry of orbiter (left) and booster (right)

Tank pressures are selected that the minimum NPSP requirements in all feedline segments are respected along the full mission; especially those at the engine entry. A variation of pressurization gas temperatures has been performed. The booster LOX tank pressure can be limited to 2.1 bar because of its forward position always generating a lot of hydrostatic pressure down the line which is beneficial for good NPSP. Due to this fortunate situation, the required oxygen gas at stage booster MECO is below $3000 \mathrm{~kg}$. The hydrogen gas mass inside the very large $2632 \mathrm{~m}^{3} \mathrm{LH} 2-$ tank is no more than $1400 \mathrm{~kg}$ because of hydrogen's low molecular mass.

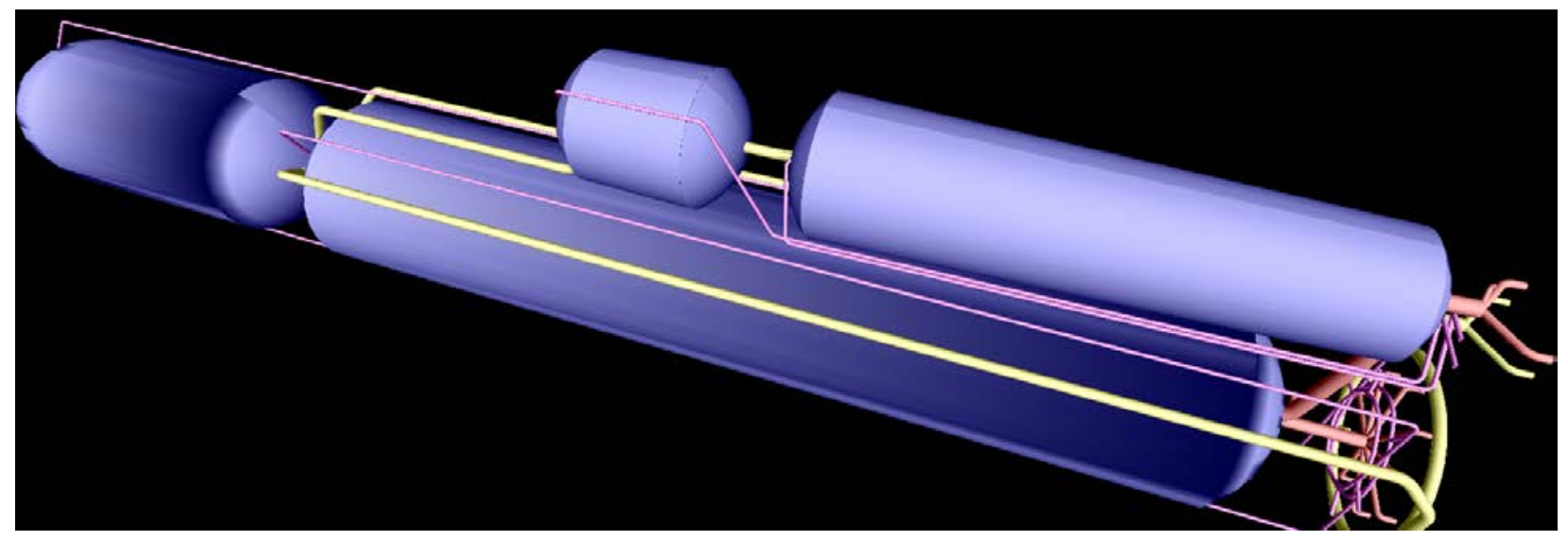

Figure 10: Preliminary definition of opellant tank and pressurization system of SpaceLiner 7-1

\section{Cabin and rescue system}

The passenger cabin of the SpaceLiner has a double role. Providing first a comfortable pressurized travel compartment which allows for horizontal entrance of the passengers, the cabin in its second role serves as a reliable rescue system in case of catastrophic events. Thus, the primary requirements of the cabin are the possibility of being firmly attached late in the launch preparation process and fast and safely separated in case of an emergency.

The capsule is able to fly autonomously back to Earth's surface in all separation cases. The abort trajectories are primarily influenced by the mass of the capsule and the aerodynamic performance with the most important 
subsystems being the separation motors, the thermal protection system (TPS), and the structure. These three subsystems have been recently investigated and sized for function, performance, and mass.

Four critical points are chosen to simulate the abort trajectory to demonstrate the SpaceLiner7 capsule is able to fly safely back to Earth during any perceived abort scenario:

- Launch pad

- Booster separation

- Highest altitude of the SpaceLiner7 orbiter

- Main engine cut-off (MECO)

Results of the trajectory simulations are presented in [32].

The separation motors are designed to separate the capsule from the orbiter, without exceeding recommended maximum acceleration limits. The following requirements are considered:

- reliability in performance

- ability to reach a safe distance in a short period of time

- ability to reach a certain altitude

- requirement to fit within the SpaceLiner7 orbiter

In order to fulfill these requirements, the SRM must provide a high acceleration in a very short period of time. Due to severe geometry constraints, it has been decided to utilize a five motor configuration. With a chamber pressure of $150 \mathrm{bar}$, an expansion ratio of 25 and a half angle of $15^{\circ}$, the length of the nozzle is slightly under $1 \mathrm{~m}$ and the entire length of one motor is approximately $1.4 \mathrm{~m}$. The motor has an approximate thrust of $800 \mathrm{kN}$ and a burn time of almost $2 \mathrm{~s}$ while the total mass of the propellant for all five motors adds up to $2.6 \mathrm{t}$ [32].

The Thermal Protection System (TPS) of the SpaceLiner7 capsule is required to withstand several different heat loads according to the different nominal and abort cases it encounters. In the course of this investigation, it has to be distinguished which areas of the capsule (i.e. the nose area, upper half or lower half) are considered. During nominal flight, the capsule is considered part of the orbiter. This means that the lower half and nose are protected by the orbiter structure and its TPS. They are therefore, not subjected to the external heat load until the capsule is separated in an abort case. In contrast, the capsule's upper half is part of the orbiter's outer shell and so is heated up during nominal flight. These differences lead to different starting conditions regarding initial temperature after abort separation.

A potential cabin pre-design and the necessary life-support system mostly driven by medical requirements have been studied. Absolutely essential is a small shell-like protection around each seat which would automatically close in case of sudden cabin pressure drop.

Overall length of the capsule without separation motors is $15.6 \mathrm{~m}$ and its maximum external height is $5.6 \mathrm{~m}$. The estimated masses are slightly less than 30 tons for the dry capsule, about $7900 \mathrm{~kg}$ for the passengers, crew and luggage, and $3400 \mathrm{~kg}$ for all propellants of separation motor and RCS. The RCS propellants could also partly be used in the nominal mission of the SpaceLiner.

\section{3. $\quad$ Structural pre-sizing}

A more detailed structural analysis of SpaceLiner7 in DLR and with the FAST20XX support of FOI from Sweden and Orbspace from Austria is progressing. Preliminary sizing of the LH2-tank as a conical CFRP structure will soon be started by the TU-Delft within the CHATT research program.

An aeroshell-like structure for the passenger stage is most promising because of decoupling the maximum thermal gradients between cryogenic tanks and the outside surface. The internal protected structure could be metallic or CFRP. The currently running investigation is focusing on conventional aluminium alloy. The Hypersonic vehicle Structural Analysis Program (HySAP) has been developed at DLR-SART which allows for fast and accurate structural pre-sizing of complicated integrated structures of hypersonic vehicles.

The main aim of the current analyses for the SpaceLiner is the identification of tendencies, rather than production of concrete mass values which will follow at a later stage. Main subjects of these investigations are [33]: 
1) Variation of stiffening concepts

2) Variation of stiffener layer thicknesses

3) Variation of materials and impact on TPS mass

4) Variation of minimum gauge thicknesses

5) Impact of considering TPS thicknesses on structural mass

6) Impact of different load cases

Free geometric variables for the structural design are only the positions of the structural members. However, the positions of some of the members have already been fixed and will not be changed. This includes fuselage frames at the beginnings and endings of the tanks and the passenger stage as well as at the booster attachment points and the main engine load introduction position. Furthermore, some wing rib and spar positions are fixed, for instance due to the predetermined main gear positions. The left part of Figure 11 shows the geometry model with the fixed structural members only. Additional members have then been added, where the fuselage frame/bulkhead spacing generally is not higher than $3 \mathrm{~m}$. The wing spars have a higher spacing. This geometry model forms the baseline configuration of the current investigations.
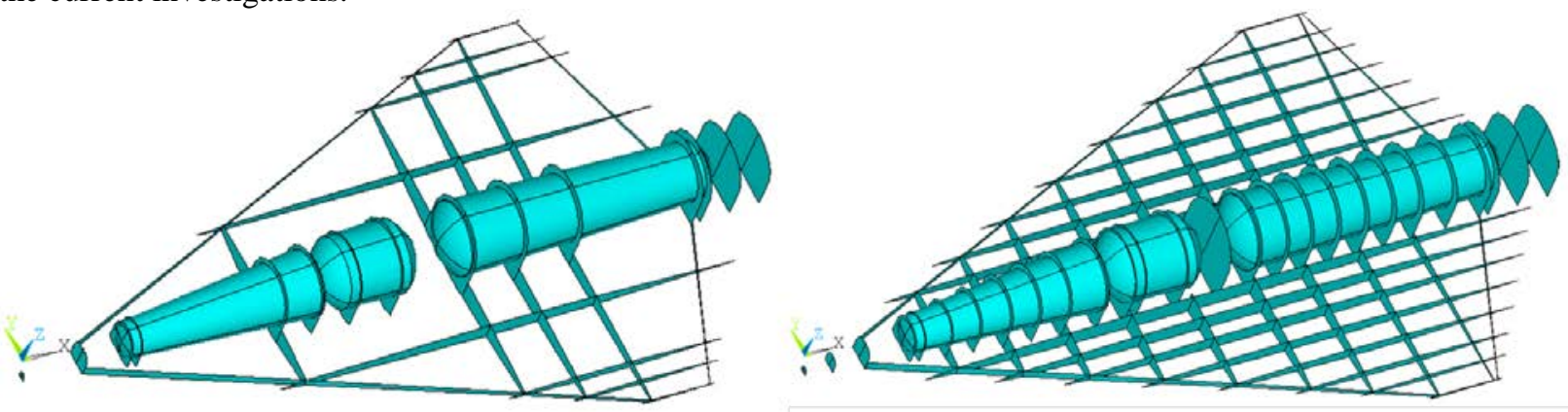

Figure 11: Baseline SpaceLiner 7-1 orbiter structural configuration with skins removed; fixed members only (left), all members (right) [33]

Orbspace is carrying out the structural assessment of the passenger capsule to obtain a conceptual structural design of the passenger capsule, in particular with respect to the window design, which is considered a critical vehicle subsystem. The two dominant load cases of the capsule are the cabin pressure and the loads from the thrust of the separation rocket motors. The sensitivity of two key design aspects has been assessed: first the structural weakening of the window holes and, second, the structural implications of a pressurized fuselage with a non-cylindrical cross section. The FE analysis is carried out with shell elements and a solver based on an iterative Fourier Finite-Element (FFE) formulation is used which takes into account large displacements. An automatic unstructured mesh is generated for a half-symmetry of the capsule with about 20000 elements and 40000 nodes. The walls are simulated with aluminum 2219 with an assumed thickness of $3 \mathrm{~mm}$ and the windows are made of acrylic with a thickness of 8 $\mathrm{mm}$.

Based on the results of the analyses presented in [32], an axi-symmetric (conic) structural concept has been chosen for the pressurized cabin. The outer aerodynamic shape should not be changed. In this layout, also the transitions between a cylindrical and two conical sections have been eliminated, which are weakening points. In this second step of structural assessments, the structural response to the loads during the firing of the escape ejection motor has been addressed. The combined thrust of all escape ejection motors is in the order of $4000 \mathrm{kN}$. This subjects the passenger capsule to an acceleration of about $10 \mathrm{~g}$. A thrust frame consisting of a cone, a ring frame and a crossbeam has been chosen to distribute these high thrust loads uniformly into the main vehicle structure. The structure itself has also been stiffened by a number of stringers and frames. The load case for the launch site abort has been chosen, because there is no differential pressure across the cabin wall which would provide a positive stiffening effect.

Figure 12 shows the von Mises stress of the simulation. The stresses are lowest at the nose tip and increase gradually towards to rear of the vehicle. They are at highest values close to the connection points of the ejection rocket motors. The results of this simulation confirm that the high loads can be introduced into the main structure quite uniformly by the selected cone design, despite its very compact height. The von Mises stresses remain less than half the tensile 
strength of the selected aluminum material. This might allow for structural improvements and weight reductions. On the other hand, the contraction forces might require additional structural stiffening to avoid local buckling.

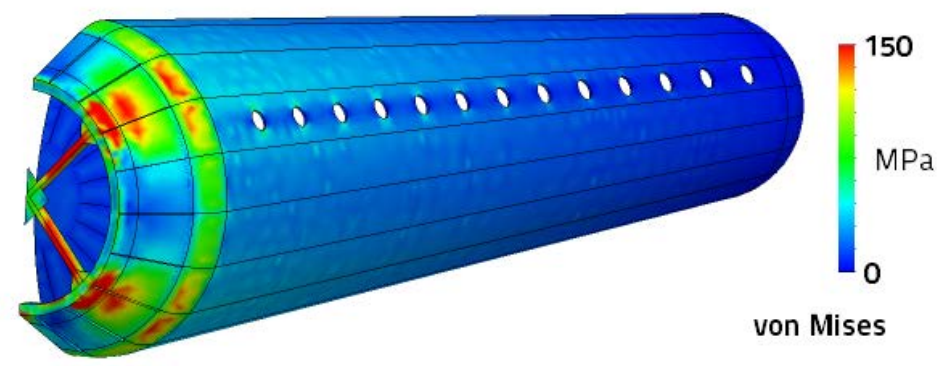

Figure 12: Von Mises stress distribution in passenger capsule in case of emergency ejection

4. Thermal protection and active cooling subsystem

A first preliminary sizing of the SpaceLiner7's Thermal Protection System (TPS) for the nominal mission has been described in [16]. However, the TPS has to withstand several different heat loads according to nominal flight and also for different abort cases. To be able to determine the heat loads for a full vehicle surface along different trajectories, fast engineering methods have to be used. HOTSOSE is a fast code for preliminary flow analyses in hypersonics based on modified Newtonian surface inclination techniques. Friction drag is estimated for each panel with the classical analytical methods for compressible laminar or turbulent flow of van Driest and White-Christoph. The surface temperatures are calculated under assumption of an adiabatic wall in radiation equilibrium. Heat fluxes are determined by using the Fay-Ridell equation close to the stagnation point and the Zoby-Moss-Sutton approach further downstream. The real gas effects on gasdynamic and transport properties can be considered in the calculation for chemically reacting air in equilibrium [2]. A fully turbulent flow along the flight path has been assumed for the TPS dimensioning as a conservative assumption. HOTSOSE calculates the heat fluxes at each mesh point at selected flight conditions with Mach number, altitude, and angle of attack known from trajectory simulations. By this approach a heat flux profile over time is obtained for the complete vehicle surface.

Due to the requirement of reusability, only non-ablative materials are suitable on the SpaceLiner's surface. According to the different maximum temperatures occurring at the different surface areas, three different materials were chosen:

- AFRSI stands for Advanced Flexible Reusable Surface Insulation and was developed as a partial replacement for FRSI and LRSI on the Space Shuttle orbiter. It is easier to maintain and withstands temperatures of up to $922 \mathrm{~K}$. AFRSI, as currently selected for the SpaceLiner, is composed of an outer fabric with C-9 coating, a Q-fiber felt insulation and an inner fabric layer and is attached to the structure with RTV adhesive.

- CRI is the abbreviation of "Conformable Reusable Insulation". It consists of a metal fabric layer (for example Inconel 617) and a ceramic Nextel 440 fabric within between an alumina flexible insulation (for example SAFFIL). The maximum used-temperature is about $1300 \mathrm{~K}$.

- The multi-layer CMC-Alumina insulation is a composite of a ceramic matrix composite and fibres. Typically the fibres are carbon and the matrix is siliciumcarbide. The insulation material is ZIRCAR Alumina Mat, because it has a low density and a low conductivity. The thickness of the CMC cover is kept at $6 \mathrm{~mm}$ with the potential option of reducing the thickness. The maximum temperature for CMC is $2000 \mathrm{~K}$ and for the alumina insulation $1923 \mathrm{~K}$.

The maximum acceptable temperature of any passive TPS on the SpaceLiner is $1850 \mathrm{~K}$. The leading edge and nose areas exceed this limit and need an advanced active cooling (see below). Optimizing the material thickness for each of the thousands of mesh points on the vehicle would be excessively computational intensive. Additionally, this would yield a design without sufficient margin on the TPS thickness and which would be unpractical for manufacturing. Therefore, the vehicle surface is divided into a number of different regions, depending on the overall maximum temperature for all nominal and abort trajectories. To determine the optimum thickness of every area, TOP2, another in-house tool is used. It provides additionally the masses and corresponding CoGs of the different TPS areas (see Figure 13). 


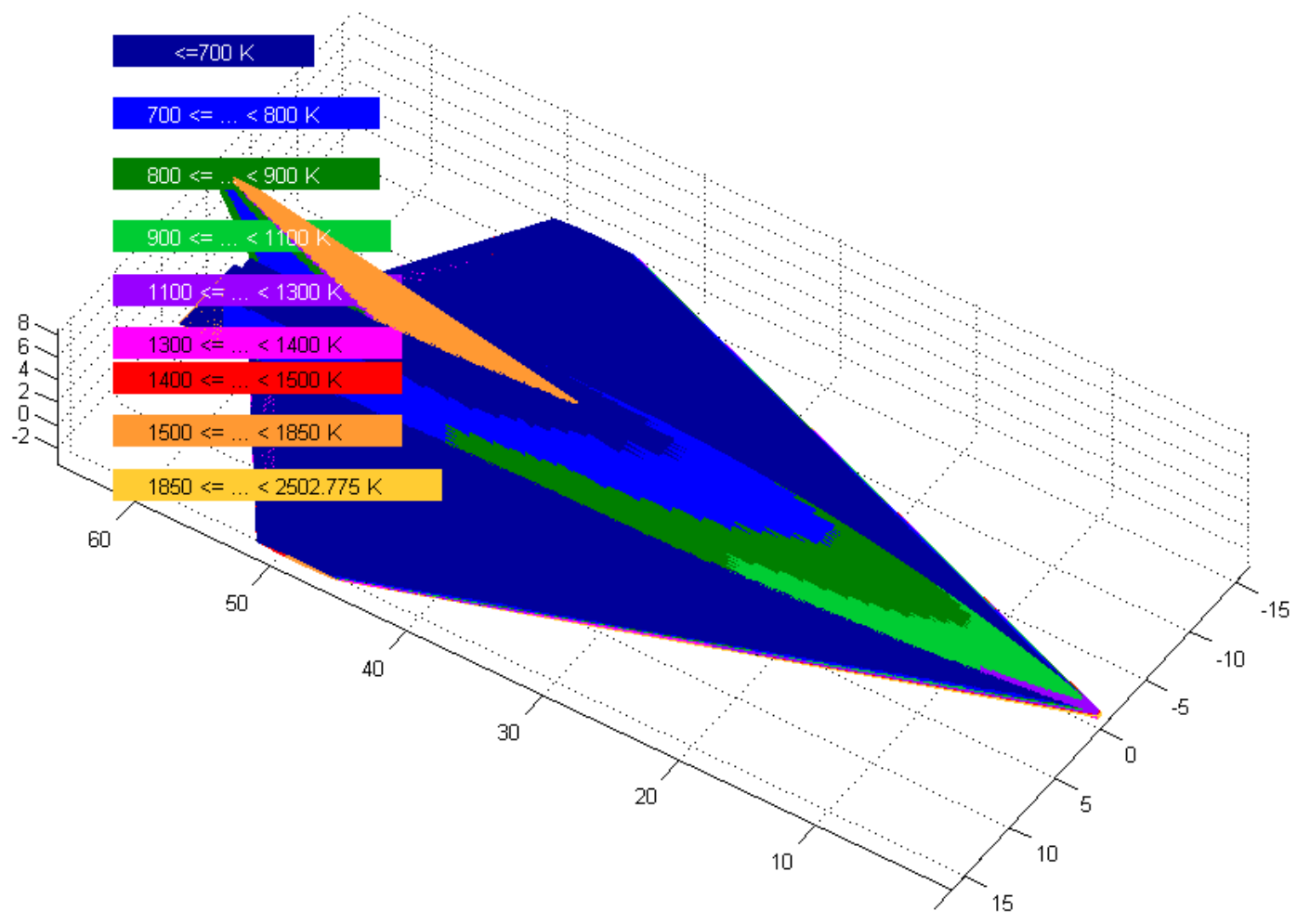

Figure 13: Overall maximum surface temperature areas reached on the upper half (considering nominal and abort trajectories)

The maximum acceptable temperatures for the passive TPS is limited to approximately $1850 \mathrm{~K}$ to be compliant with the reusability requirement. The structure is set to be allowed to heat up to $530 \mathrm{~K}$. This leads to a total TPS mass of approximately 29.6 tons already including system mass margin.

In those areas where the heatflux and temperatures exceed acceptable values CMC can withstand, transpiration cooling using liquid water is foreseen $[2,12,16]$. This relatively small area is highlighted in Figure 14 in violet color. In FAST20XX this innovative method has been experimentally tested in DLR's arc heated facility in Cologne using subscale probes of different porous ceramic materials. Tests are still ongoing but results of cooling efficiency are in good agreement with earlier research $[2,12]$ using a different material. The pressure drop of the cooling flow going through the leading edge or nose wall material is no more than 200 or $300 \mathrm{kPa}$. A numerical simulation of the transpiration cooling is ongoing.

Although this advanced cooling process is still at a TRL of 3, a first preliminary active cooling pre-design has been started at DLR-SART for the SpaceLiner geometry. Approximately $10000 \mathrm{~kg}$ of water are needed for cooling during a nominal mission. The transpiration of $\mathrm{H}_{2} \mathrm{O}$ is already starting during the final phase of the powered orbiter flight when leading edge temperatures are already becoming excessively high. A water storage tank system, a feedline manifold including control and check-valves and some bypass and redundancy lines are sized for accommodation inside the SpaceLiner volume. It is interesting to note that already in 1970 TRW studied and pre-dimensioned a somewhat similar system under NASA contract [35].

Based on available subsystem sizing and empirical mass estimation relationships, the orbiter mass is derived as listed in Table 5. The total fluid and propellant mass includes all ascent, residual, and RCS propellants and the water needed for the active leading edge cooling. The stages' MECO mass is approximately 162.6 Mg. The SpaceLiner 71's GLOW reaches now more than $1830 \mathrm{Mg}$ (Table 6) for the reference mission Australia - Europe. This relatively large value is still below that of the Space Shuttle STS of more than $2000 \mathrm{Mg}$ and therefore technically within reach. 


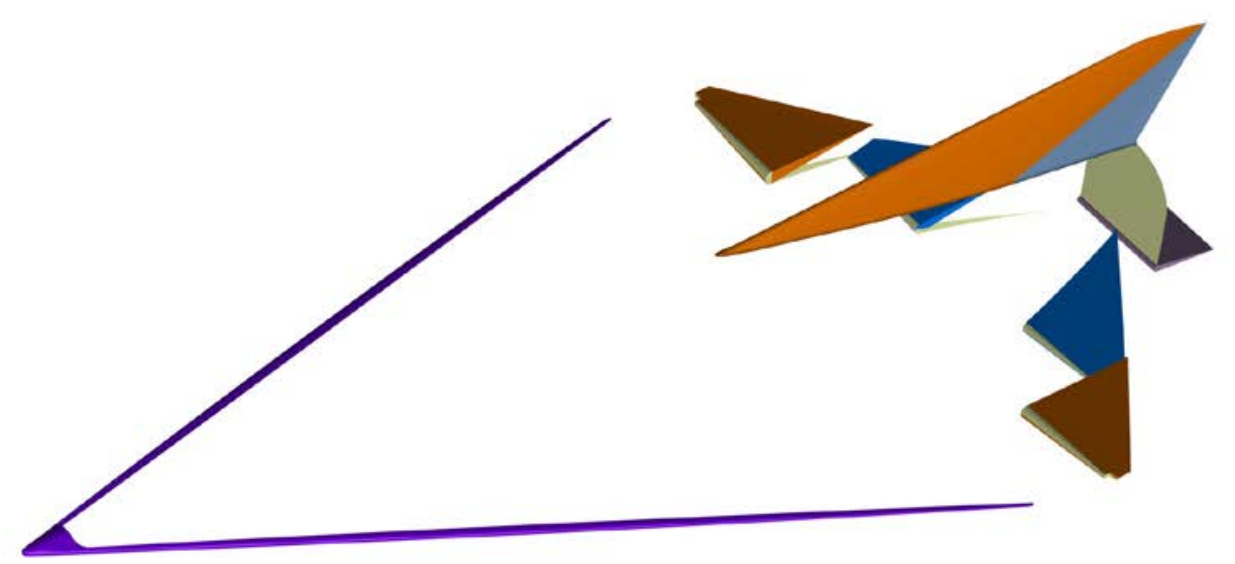

Figure 14: Actively cooled regions on SpaceLiner 7 relative to aerodynamic control surfaces

Table 5: Mass data of SpaceLiner 7-1 orbiter stage

\begin{tabular}{|c|c|c|c|c|c|c|}
\hline $\begin{array}{c}\text { Structure } \\
{[\mathrm{Mg}]}\end{array}$ & $\begin{array}{c}\text { Propulsion } \\
{[\mathrm{Mg}]}\end{array}$ & $\begin{array}{c}\text { Subsystems } \\
\text { including } \\
\text { cabin }[\mathrm{Mg}]\end{array}$ & TPS [Mg] & $\begin{array}{c}\text { Total dry } \\
{[\mathrm{Mg}]}\end{array}$ & $\begin{array}{c}\text { Total fluid \& } \\
\text { propellant } \\
\text { loading }[\mathrm{Mg}]\end{array}$ & $\begin{array}{c}\text { GLOW incl. } \\
\text { passengers \& } \\
\text { payload[Mg] }\end{array}$ \\
\hline 56.3 & 10.1 & 43.5 & 29.9 & 139.7 & 229.6 & 377.6 \\
\hline
\end{tabular}

Table 6: Mass data of SpaceLiner 7-1 launch configuration

\begin{tabular}{|c|c|c|}
\hline $\begin{array}{c}\text { Total dry } \\
{[\mathrm{Mg}]}\end{array}$ & $\begin{array}{c}\text { Total } \\
\text { propellant } \\
\text { loading }[\mathrm{Mg}]\end{array}$ & $\begin{array}{c}\text { GLOW incl. } \\
\text { passengers \& } \\
\text { payload }[\mathrm{Mg}]\end{array}$ \\
\hline 304.7 & 1520 & 1832.5 \\
\hline
\end{tabular}

D. Nominal trajectory

Several trajectory options have been traded for the Australia - Europe reference mission. These are all following a standard launch vehicle vertical ascent with an initial azimuth in North-Eastern direction overflying the arctic sea before approaching Europe from the North-Eastern Atlantic. This is the same baseline trajectory which has been established for the SpaceLiner 4 using ASTOS optimizations [15]. Maximum speed of the vehicle is around 7.1 $\mathrm{km} / \mathrm{s}$ at $69 \mathrm{~km}$ and the flight path angle $\gamma$ at MECO is close to $0^{\circ}$ (Figure 15). Then the propulsive phase is directly followed by hypersonic gliding.

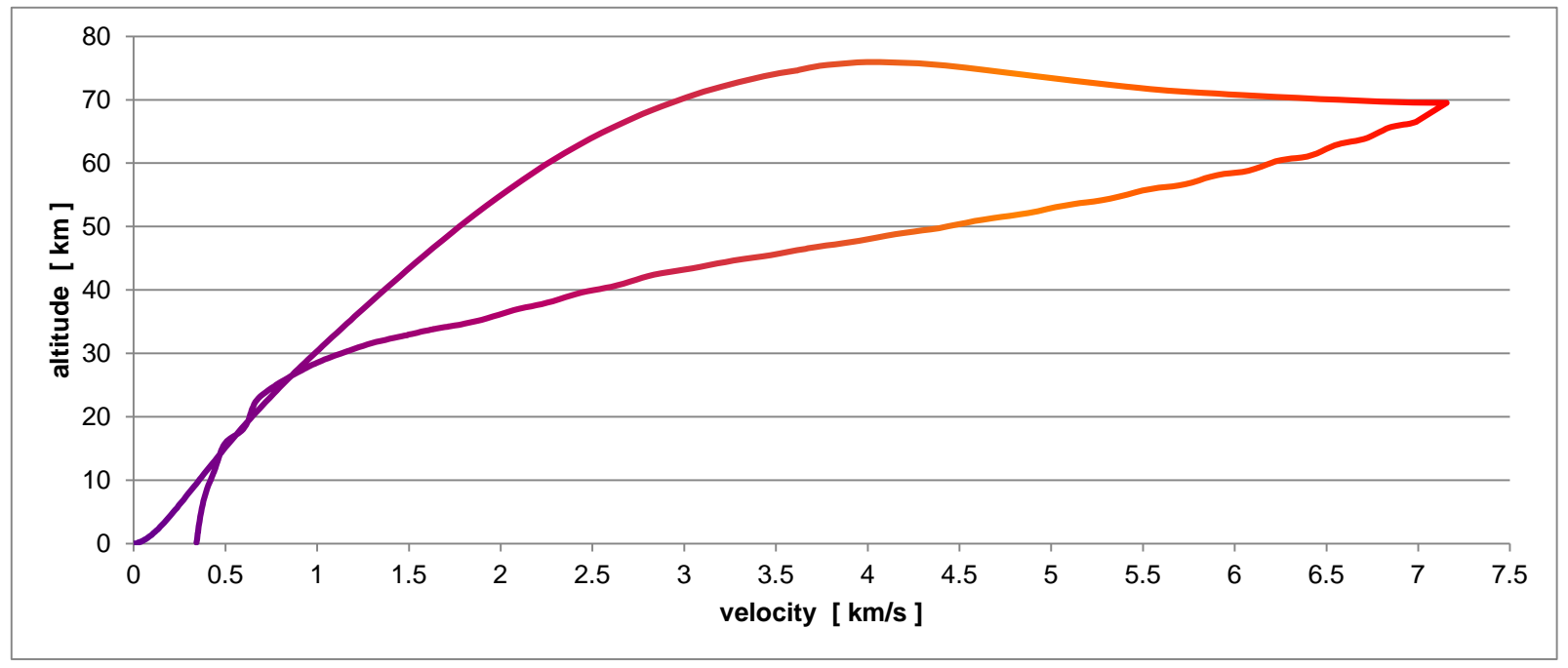

Figure 15: Nominal reference trajectory of SpaceLiner 7-1 
An alternative option is a trajectory with a few degrees of $\gamma$ in this point which would result in a ballistic arc duration of a couple of minutes for the SpaceLiner. The vehicle would travel during this phase more than $1000 \mathrm{~km}$ almost outside of the atmosphere at very low drag. However, in order to avoid excessive heatrates, an increased angle-of-attack is subsequently needed at lower altitudes which has a strongly decelerating effect. A definitive answer on the best trajectory requires detailed system studies taking into account flight path optimization, adapted TPS-sizing, and reliable data on the friction drag in low atmospheric density. The Italian aeronautical research establishment CIRA is performing DSMC calculations of the SpaceLiner at high altitudes which provides drag coefficients under these conditions [20].

\section{Conclusion}

The DLR proposed reusable winged rocket SpaceLiner for very high-speed intercontinental passenger transport is constantly maturing in its conceptual design. Research on the vehicle is performed with support from the EU projects FAST20XX and CHATT with several European partners. Assuming advanced but not exotic technologies, a vertically launched rocket powered two stage space vehicle is able to transport about 50 passengers over distances of up to $17000 \mathrm{~km}$ in about 1.5 hours.

The potential intercontinental SpaceLiner missions have been subdivided into three classes of which class 1 is the ambitious Australia - Europe reference flight presented in this paper. A variable engine mixture ratio along the ascent is able to boost average Isp-performance and allows for saving several ten tons of fuel.

The environmental impact of the SpaceLiner has been preliminarily investigated in FAST20XX. The atmospheric pollution is very small compared to airliner traffic. Also the effect on the Earth's climate seems to be low, however, with some uncertainty for water deposition at mesospheric altitudes. The launch and ascent noise as well as the sonic boom reaching ground are most critical for a viable SpaceLiner operation in the future. The selection of potential SpaceLiner launch and landing sites will likely be influenced by constraints due to generated noise.

The latest iteration step of the SpaceLiner concept is the version 7 which is based more and more on preliminary design of different subsystems and vehicle structures. An integrated interdisciplinary design process of the passenger stage is ongoing and has already delivered a convergent configuration named 7-1. The paper presents the latest investigation status on major subsystems like the full-flow staged combustion main engine, the tank-, feed- and pressurization system, the integrated passenger cabin and rescue capsule, and the thermal protection- and active cooling subsystem.

Work on the visionary SpaceLiner concept is gaining momentum in the European aerospace community.

\section{Acknowledgements}

Part of this work was performed within the 'Future High-Altitude High-Speed Transport 20XX' project investigating high-speed transport. FAST20XX, coordinated by ESA-ESTEC, is supported by the EU within the 7th Framework Programme Theme7 Transport, Contract no.: ACP8-GA-2009-233816.

Further information on FAST20XX can be found on http://www.esa.int/fast20xx.

Part of this work was performed within the 'Cryogenic Hypersonic Advanced Tank Technologies' project investigating tank technologies for high-speed transport. CHATT, coordinated by DLR-SART, is supported by the EU within the 7th Framework Programme Theme 7 Transport, Contract no.: ACP1-GA-2011-285117. Further information on CHATT can be found on http://www.chatt.aero

The authors gratefully acknowledge the contributions of Ms. Carina Ludwig, Mr. Alexander Kopp, Mr. Ryoma Yamashiro, Mr. Magni Johannsson, Mr. David Gerson, Mr. Jochen Bütünley, Mr. Benjamin Hintz, Mr. Ola Rasmusson, Mr. Francesco Cremaschi and Mr. Rafael Molina to the preliminary design of the SpaceLiner. 


\section{References}

1. Sippel, M., Klevanski, J., Steelant, J.: Comparative Study on Options for High-Speed Intercontinental Passenger Transports: Air-Breathing- vs. Rocket-Propelled, IAC-05-D2.4.09, October 2005

2. Sippel, M., Klevanski, J., van Foreest, A., Gülhan, A., Esser, B., Kuhn, M.: The SpaceLiner Concept and its Aerothermodynamic Challenges, $1^{\text {st }}$ ARA-Days, Arcachon July 2006

3. Sippel, M.; Klevanski, J.: Preliminary Definition of the Supersonic and Hypersonic Airliner Configurations in LAPCAT, AIAA 2006-7984, $14^{\text {th }}$ Spaceplanes Conference, November 2006

4. van Foreest, A., Sippel, M., Klevanski, J., Gülhan, A., Esser, B.: Technical Background and Challenges of the SpaceLiner Concept, $7^{\text {th }}$ International Symposium on Launcher Technologies, Barcelona, Spain, April 2-5, 2007

5. Sippel, M.: Introducing the SpaceLiner Vision, $7^{\text {th }}$ International Symposium on Launcher Technologies, Barcelona, Spain, April 2-5, 2007

6. Sippel, M., van Foreest, A.: Latest Progress in Research on the SpaceLiner High-Speed Passenger Transportation Concept, IAC-07-D2.7.07, September 2007

7. van Foreest, A.; Sippel, M.: The Logistical Challenges of the SpaceLiner Concept, IAA $1^{\text {st }}$ Symposium on Private Human Access to Space, Arcachon May 28-30 2008

8. Sippel, M.: Promising roadmap alternatives for the SpaceLiner, Acta Astronautica, Vol. 66, Iss. 11-12, (2010)

9. NN: SEVENTH FRAMEWORK PROGRAMME, THEME 7 [Transport, Aeronautics], Grant agreement for: Collaborative Project, small or medium scale focused research project1, Annex I - "Description of Work", Project acronym: FAST20XX, Project full title: Future high-Altitude high-Speed Transport 20XX, Grant agreement no.: 233816, 06 January 2009

10. Sippel, M.: SpaceLiner - a Visionary Concept of an Ultra Fast Passenger Transport under Investigation in FAST20XX, AIAA 2009-7439, $16^{\text {th }}$ AIAA/DLR/DGLR International Space Planes and Hypersonic Systems and Technologies Conference, Bremen 2009

11. Sippel, M., van Foreest, A.: SpaceLiner Rocket-Powered High-Speed Passenger Transportation Concept Evolving in FAST20XX, IAC-10-D2.4.06, September 2010

12. Van Foreest, A. , Sippel, M.; Gülhan, A.; Esser, B.; Ambrosius, B.A.C.; Sudmeijer, K.: Transpiration Cooling Using Liquid Water, Journal of Thermophysics and Heat Transfer, Vol. 23, No. 4, October-December 2009

13. Kopp, A.; van Foreest, A., Sippel, M.; Dalenbring, M.; Jarlas, R.: Investigation of Structure for the Hypersonic Transport System SpaceLiner, AIAA 2011-2373, $17^{\text {th }}$ AIAA International Space Planes and Hypersonic Systems and Technologies Conference, April 2011

14. Neeb, D., Schwanekamp, T., Gülhan, A.: Preliminary Aerodynamic Shape Optimization of the SpaceLiner by Means of Engineering Methods, AIAA 2011-2299, $17^{\text {th }}$ AIAA International Space Planes and Hypersonic Systems and Technologies Conference, April 2011

15. Sippel, M. van Foreest, A.; Bauer, C.; Cremaschi, F.: System Investigations of the SpaceLiner Concept in FAST20XX, AIAA 2011-2294, $17^{\text {th }}$ AIAA International Space Planes and Hypersonic Systems and Technologies Conference, April 2011

16. Sippel, M.; van Foreest, A.; Dietlein, I.; Schwanekamp, T.; Kopp, A.: System Analyses Driving Improved Aerothermodynamic Lay-out of the SpaceLiner Configuration, ESA-SP692, May 2011

17. Corriveau, L.: Pre-Design on the SpaceLiner7’s Reusable Booster Stage, SART TN-015/2011, 2012

18. Sippel, M.; Yamashiro, R.; Cremaschi, F.: Staged Combustion Cycle Rocket Engine Design Trade-Offs for Future Advanced Passenger Transport, ST28-5, SPACE PROPULSION 2012, Bordeaux, 7th - 10th May 2012

19. Sippel, M.; Kopp, A.; Sinko, K.; Mattsson, D.: Advanced Hypersonic Cryo-Tanks Research in CHATT, AIAA5945, $18^{\text {th }}$ AIAA International Space Planes and Hypersonic Systems and Technologies Conference, Tours, September 2012

20. Sippel, M.; Votta, R.: Advanced Launcher Technology Maturation Supported by EU-Aeronautic Research Projects, IAC-12-D2.5.6, Naples, October 2012

21. Eldred, K.: Acoustics Loads Generated by the Propulsion System, NASA-SP8072, 1971

22. NN: Final Constellation Programmatic Environmental Impact Statement, Release 08-028, NASA 2008

23. Plotkin, K.: Computer models for sonic boom analysis: PCBoom4,CABoom, BooMap, CORBoom, Wyle Report WR 02-11, 2002 
24. Maglieri, D.J.; Henderson, H.R.; Massey, S.J.; Stansbery, E.G.: A Compilation of Space Shuttle Sonic Boom Measurements, NASA/CR-2011-217080, April 2011

25. NN: IPCC Third Assessment Report Climate Change 2001: The Physical Science Basis

26. Stenke, A.; Grewe, V.: Simulation of stratospheric water vapor trends: impact on stratospheric ozone chemistry, Atmospheric Chemistry and Physics, 5, 2005.

27. Grewe, V. et.al.: Climate functions for the use in multi-disciplinary optimisation in the pre-design of supersonic business jet.” The Aeronautical Journal 114 no 1154, April 2010

28. Sippel, M.; Klevanski, J.; Kauffmann, J.: Innovative Method for Return to the Launch Site of Reusable Winged Stages, IAF-01-V.3.08, 2001

29. Sippel, M.; Klevanski, J.: Simulation of Dynamic Control Environments of the In-Air-Capturing Mechanism, $6^{\text {th }}$ International Symposium on Launcher Technology 2005, B1.4

30. Sippel, M.; Klevanski, J.; Atanassov, U.: Search for Technically Viable Options to Improve RLV by Variable Wings, IAC-04-V.8.07, 2004

31. Schwanekamp, T.; Bauer, C.; Kopp, A.: The Development of the SpaceLiner Concept and its Latest Progress, $4^{\mathrm{TH}}$ CSA-IAA CONFERENCE ON ADVANCED SPACE TECHNOLOGY, Shanghai, September 2011

32. Bauer, C.; Garbers, N., Johannsson, M.; Lentsch, A.: INVESTIGATIONS OF THE SPACELINER PASSENGER CAPSULE AND VARIOUS ABORT SCENARIOS, DLRK 2012, September 2012

33. Kopp, A.; Garbers, N.; Jarlas, R.: Parametric Structural Analysis for the SpaceLiner, AIAA-5944, $18^{\text {th }}$ AIAA International Space Planes and Hypersonic Systems and Technologies Conference, Tours, September 2012

34. Schwanekamp, T.; Bütünley, J.; Sippel, M.: Preliminary Multidisciplinary Design Studies on an Upgraded 100 Passenger SpaceLiner Derivative, AIAA-5808, $18^{\text {th }}$ AIAA International Space Planes and Hypersonic Systems and Technologies Conference, Tours, September 2012

35. Johnston, C. G.; Gomet, A. V.: RADIATIVE, ABLATIVE, AND ACTIVE COOLING THERMAL PROTECTION STUDIES FOR THE LEADING EDGE OF A FIXED-STRAIGHT WING SPACE SHUTTLE, PART V: TRANSPIRATION COOLED HEAT SHIELDS PERFORMANCE, NAS 9-81 66, Houston, 31. DECEMBER 1970

Further updated information concerning the SART space transportation concepts is available at: http://www.dlr.de/SART 